\title{
Metabolic Long-Term Monitoring of Transcorneal Electrical Stimulation in Retinitis Pigmentosa
}

\author{
Nesrin Meral ${ }^{a}$ Olga Zabek ${ }^{a}$ Hanna Camenzind Zuche ${ }^{a} \quad$ Ursula Müller $^{a}$ \\ Dominique Prétot ${ }^{b}$ Annekatrin Rickmannc Hendrik P.N. Scholla, d \\ Maria della Volpe Waizel ${ }^{a, b, c}$ \\ ${ }^{a}$ Department of Ophthalmology, University of Basel, Basel, Switzerland; ${ }^{b}$ Eye Clinic Heuberger, Olten, Switzerland;

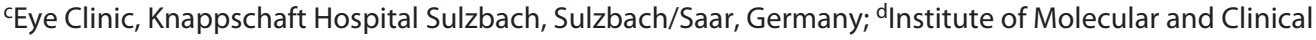 \\ Ophthalmology Basel (IOB), Basel, Switzerland
}

\section{Keywords}

Retinal vessel oximetry $\cdot$ Inherited retinal diseases ·

OkuStim · Transcorneal electrical stimulation · Retinitis

pigmentosa

\begin{abstract}
Introduction: Transcorneal electrical stimulation (TES) is a new therapeutical approach for retinitis pigmentosa (RP). With progression of RP, degeneration of photoreceptors results in lower oxygen consumption of the retina. Retinal oximetry $(R O)$ is a noninvasive method to analyze oxygen saturation in retinal vessels and has shown promising short-term results as a therapy monitoring tool for TES. The aim of our study was to measure the long-term effects of TES on RO parameters over a period of 3 years (3Y). Methods: A total of 18 eyes of 9 subjects (5 $4 \sigma^{\prime}$ ) suffering from RP were examined at baseline (BL), 6 months, and 3 Y of TES (OkuStim ${ }^{\circledR}$ ) treatment. TES was performed for 30 min once a week at $200 \%$ of the individual phosphene threshold simultaneously on both eyes. The oxygen saturation was examined at BL and following TES therapy with the oxygen saturation tool of the Retinal Vessel Analyser (IMEDOS Systems UG, Jena, Germany). The global oxygen saturation parameters
\end{abstract}

karger@karger.com www.karger.com/ore

Karger $\stackrel{\text { ' }}{=}$
(C) 2021 The Author(s)

Published by S. Karger AG, Basel

This article is licensed under the Creative Commons Attribution 4.0 International License (CC BY) (http://www.karger.com/Services/ OpenAccessLicense). Usage, derivative works and distribution are permitted provided that proper credit is given to the author and the original publisher. (in \%), within 1.0-1.5 optic-disc diameters from the disc margin, in retinal arterioles $\left(\mathrm{A}-\mathrm{SO}_{2}\right)$ and venules $\left(\mathrm{VSO}_{2}\right)$ were measured and their difference $\left(\mathrm{A}-\mathrm{V} \mathrm{SO}_{2}\right)$ was calculated. In addition, we recorded the diameters in the main arterioles (D-A) and venules $(D-V)$. ANOVA-based linear mixed-effects models were employed for statistical analysis using SPSS ${ }^{\circledR}$. Results: After $3 \mathrm{Y}$ of

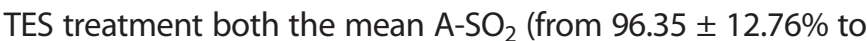
$100.89 \pm 5.87 \%, p=0.22$ ) and $\mathrm{V} \mathrm{SO}_{2}$ (from $62.20 \pm 11.55 \%$ to $64.55 \pm 8.24 \%, p=0.77)$ increased slightly. The $\mathrm{A}-\mathrm{V} \mathrm{SO}_{2}$, which corresponds to the oxygen consumption of the retina, presented also with a slight increment from $34.15 \pm 9.68 \%$ at BL to 36.23 $\pm 7.71 \%$ without reaching statistical significance $(p=0.27)$. TES also did not appear to alter the vascular diameter parameters, D-A and D-V $(p>0.05)$. Conclusion: Our long-term observations indicate that TES therapy in RP might lead to a slight increment in oxygen consumption of the retina. However, a larger cohort and longer duration may be needed to adequately power a follow-up study and to confirm this trend reflecting a possible benefit of TES for RP.

(c) 2021 The Author(s)

Published by S. Karger AG, Basel

Nesrin Meral and Olga Zabek contributed equally to this work.
Correspondence to:

Maria della Volpe Waizel, maria.waizel@gmail.com 


\section{Introduction}

Transcorneal electrical stimulation (TES) is a new therapy option for patients suffering from retinitis pigmentosa (RP) $[1,2]$. RP is a heterogenous inherited retinal disease characterized by a rod-cone degeneration leading to progressive visual deterioration. TES seems to induce the release of neurotrophic factors which help the remaining retinal cells to survive [2-9]. The TES-pivotal trial and the corresponding follow-up study presenting 1 -year data provided a more detailed explanation. However, the underlying mechanisms are not yet fully understood $[1,2]$.

It is known that changes of the retinal vasculature with neurovascular remodeling are a hallmark of RP [10-21]. Oxygen is an essential metabolite for retinal photoreceptors in order to maintain an intact visual function [2224]. In RP, due to cellular apoptosis, a reduction of the retinal oxygen consumption with a consecutive increase in the retinal vessel oxygen saturation values was observed [10-21, 25]. By measuring the therapeutic effect on the retinal oxygen consumption, a recent pilot study presenting short-term effects after 6 months $(6 \mathrm{M})$ of TES found that retinal vessel oximetry $(\mathrm{RO})$ might be superior to full-field electroretinography (ffERG) or visual field (VF) as a biomarker in evaluating the treatment of TES in RP patients with a short-lasting, noninvasive, contactfree, and patient-friendly measurement [25]. This study could show a significantly increased oxygen consumption of the remaining photoreceptors of the retina which might reflect a positive therapeutic response to TES [25]. However, so far, no long-term data are available for the usage of RO as a monitoring tool in the context of TES. Recent studies with patients suffering from neovascular age-related macular degeneration or diabetic macular edema under anti-VEGF therapy demonstrated that RO might be a reliable technique for evaluating the treatment effect by its oxygen metabolic response $[23,24]$. Therefore, the aim of our study was to compare retinal vessel oxygen saturation parameters in RP patients undergoing TES therapy over a long-term period of up to 3 years (3Y) in order to find changes that would be attributed to the therapeutic intervention.

\section{Materials and Methods}

This prospective study was performed from January 2018 until May 2021 in a single tertiary care center (University of Basel, Department of Ophthalmology, Switzerland) on a total of 18 eyes from 9 subjects suffering from RP. Approval of the local authorities
(Ethics Commission of Central and Northern Switzerland, EKNZ, Basel, Switzerland) was obtained with a positive vote for prospective observational investigation (trial number EKNZ BASEC 202000122).

The inclusion criteria for all study participants were as follows: Caucasian origin, refractive spherical equivalent error $\leq 6$ diopters of myopia or hyperopia, no history of ocular surgery, implants as pacemakers, or any other ocular or systemic pathology (intraocular treatment as vitreoretinal surgery, diabetic retinopathy, retinal or choroidal neovascularization, exudative age-related macular degeneration, glaucoma, history of retinal detachment, diseases of the optic nerve, systemic diseases as diabetes mellitus, systemic hypertension, or neurological diseases) that might influence the RO measurements. To be included for TES, all RP patients had to meet criteria as follows: clinical and electrophysiological diagnosis of RP, absence of macular edema, a residual central VF $\geq 10^{\circ}$ visual angle, no further contraindications to TES therapy. Exclusion criteria were as follows: fundus oximetry images of poor quality, unstable TES treatment performance, or expressed unwillingness to participate in the study. All research procedures were performed in accordance with institutional guidelines and the Declaration of Helsinki. Written informed consent was obtained before examination. All patients underwent a detailed ophthalmic examination at baseline (BL), $6 \mathrm{M}$, and (3Y of TES treatment which included refraction, best-corrected visual acuity measured under standardized Early Treatment Diabetic Retinopathy Study (ETDRS ) conditions, slit-lamp examination, biomicroscopy, fundoscopy in mydriasis, fundus autofluorescence, VF testing with semi-automated kinetic perimetry (V4e, III4e, I4e, III3e isopters tested with Octopus $900^{\circledR}$, Haag-Streit AG Bern, Switzerland), and ffERG (Diagnosys LLC Espion system; ISCEV standard [26]. Furthermore, if approved by the patient's health insurance, also a molecular genetic assessment was included. In RP patients with extinguished ffERG at BL, electrophysiological testing was not repeated at the $6 \mathrm{M}$ and $3 \mathrm{Y}$ follow-up. All patients were recruited from the hospital's hereditary retinal degeneration consultation hour and were diagnosed by 2 experienced fellowshiptrained retina specialists (M.d.V.W. and H.P.N.S.). Tropiphen eye drops (tropicamide $0.5 \%$ and phenylephrine $1 \%$, formula of our institutional pharmacy) were used to widen both pupils before $\mathrm{RO}$ measurements. Three drops were applied at 10 -min intervals in each eye.

\section{Transcorneal Electrical Stimulation}

TES (OkuStim ${ }^{\circledR}$, Retina Implant, Reutlingen, Germany) was performed according to the guidelines of the pivotal trial [1]. The OkuStim ${ }^{\circledR}$ system consists of 3 parts: a stimulation box, a special frame that is adjusted to the patient's face, and electrodes that are placed in the frame to ensure good contact with the conjunctival tissue of the lower eyelid and the inferior bulbar conjunctiva for low impedance during TES-threshold measurement and stimulation. For a stable positioning in the frame, standard DTL-based electrodes are employed with an additional stirrup. On the ipsilateral side of the forehead, a ground-red dot electrode (3M Europe, Diegem, Belgium) is attached. Prior stimulation for each patient, an individual electrical phosphene threshold is determined by a single skilled operator in a darkened room on each eye individually in 3 independent measurements per eye (U.M.). These stimulation parameters are then programmed onto a patient's USB stick, which is plugged into the OkuStim TES device. Stimulation 
is performed once a week for $30 \mathrm{~min}$ on both eyes at $20 \mathrm{~Hz}$ with current-balanced $5 \mathrm{~ms}$-positive deflections followed by $5 \mathrm{~ms}$ negative deflections at 200 percent of the electrical phosphene threshold over a period of 3Y. The patient could choose between a supervised TES stimulation in the hospital or a nonsupervised TES stimulation at home. In order to ensure a reliable and safe TES treatment, especially in the setting of a home stimulation, the patient and an additional relative of her/him need to be thoroughly instructed. If needed, the instruction is repeated until a safe handling can be ensured. The OkuStim box is programmed to halt stimulation automatically in case the impedance increases for security reasons. Before study inclusion, all patients' TES stimulation parameters (duration, timing, impedance, and frequency of all stimulation sessions) were recorded and evaluated for consistency.

\section{RO Acquisition}

RO was performed at the BL visit before TES initiation, $6 \mathrm{M}$, and $3 \mathrm{Y}$ after first stimulation. For RO, we used a spectrophotometric oximetry filter (IMEDOS Systems UG, Jena, Germany; Fundus camera FF450, Carl Zeiss Meditec AG, Jena, Germany). Fundus photos were captured using a camera system that included a DCC Digital Camera KY-F75 (JVC Inc., Yokohama, Japan) and a Zeiss fundus camera using a 50-degree camera angle. The system's software (VISUALIS; IMEDOS Systems UG) distinguishes oxygenated hemoglobin from deoxygenated hemoglobin based on differential light imaging features at particular wavelengths, thus allowing the oxygen saturation level in the inspected retinal vessel to be measured. The acquisition of oximetry imaging is performed at 2 wavelengths: at the green channel $(548 \pm 10 \mathrm{~nm})$ to capture the oxygen-insensitive image, and at the red channel $(610 \pm 10 \mathrm{~nm})$ to capture the oxygen-sensitive image $[13,27]$. Two concentric rings, 1 with a radius of 1.0 optic-disc diameters and the other with a radius of 1.5 optic-disc diameters, are formed in the peripapillary area using an optic disc-centered imaging procedure. The area of interest, represented by the region between these 2 circles, was where we took all measurements (as labeled in Fig. 1). Four test retest fundus images for each eye were obtained [20, 21, 25, 28, 29]. Only 1 image with optimal illumination was chosen for further analysis, with red channel lighting 160 steps of the scale and green channel lighting $>60$ step of the scale. We selected manually for analyses all main arterioles and venules within the measurement area and evaluated the global mean oxygen saturation in retinal arterioles $\left(\mathrm{A}-\mathrm{SO}_{2}\right)$ and venules $\left(\mathrm{V} \mathrm{SO}_{2}\right)$ and calculated their difference, the $\mathrm{A}-\mathrm{V} \mathrm{SO}_{2}$. In addition, the diameter of the corresponding retinal arterioles (D-A) and venules (D-V) were evaluated.

\section{Statistical Analysis}

Study endpoints were the following RO parameters: the mean arterial $\left(\mathrm{A}-\mathrm{SO}_{2} ; \%\right)$ and venous $\left(\mathrm{V} \mathrm{SO}_{2} ; \%\right)$ oxygen saturation as well as their difference (A-V SO $2 ; \%)$. In addition, the mean diameters of the retinal arterioles $(\mathrm{D}-\mathrm{A} ; \mu \mathrm{m})$ and venules $(\mathrm{D}-\mathrm{V} ; \mu \mathrm{m})$ were measured. All RO parameters were recorded at BL before stimulation and following TES at $6 \mathrm{M}$ and $3 \mathrm{Y}$ follow-up.

Histograms and Shapiro-Wilk tests were performed to ensure a normal distribution for all parameters before further statistical evaluation. SPSS ${ }^{\circledR}$ (IBM SPSS Statistics, IBM Corp., Armonk, NY, USA, version 28.0.0.0) was used to build ANOVA-based linear mixed-effects models, which are suitable for repeated assessments since they allow for the consideration of the left and right eye dependency of the same participant. The eye, the refractive spherical

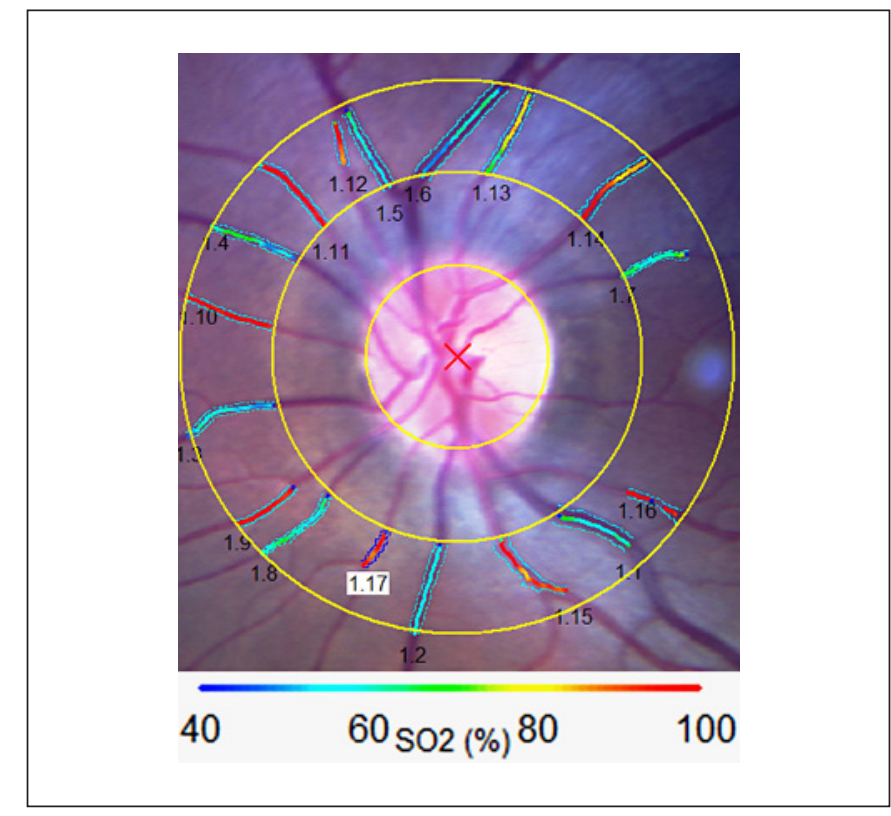

Fig. 1. An example for a RO measurement in a left eye of a healthy subject is given. All RO parameters were calculated in the main first and second branch retinal arterioles and venules within a 1.01.5 optic-disc diameter distance from the optic-disc margin. The horizontal color bar indicates the oxygen saturation levels in the corresponding vessels in $\% \mathrm{SO}_{2}$. $\mathrm{RO}$, retinal oximetry.

equivalent, and the follow-up-effect were considered to predict the effect of TES on oximetry estimations at different follow-up visits (BL, 6M, and 3Y), where the eye, refraction, and the follow-up were treated as fixed factors and the subject as a random factor. The results are presented as mean and standard deviation for all parameters with the corresponding $p$ values. $p<0.05$ was defined as statistically significant. All pairwise comparisons with ANOVA were Bonferroni adjusted.

\section{Results}

Altogether, 18 eyes were enrolled in the study of 9 patients diagnosed with RP (5 94 o'; 9 right eyes and 9 left eyes, mean age $45.09 \pm 11.13$ years, range 33-67 years). Eight patients performed a nonsupervised TES stimulation at home after a thorough instruction, 1 patient received a supervised TES stimulation in the hospital. Throughout the time course of $3 \mathrm{Y}$ TES treatment, both the visual acuity (BCVA) and the VF did not show any significant change: at $\mathrm{BL}, \log \mathrm{MAR} B C V A$ was $0.23 \pm 0.21$, after $6 \mathrm{M}$ of TES treatment BCVA slightly changed to 0.35 $\pm 0.30(p=0.32)$ and to $0.20 \pm 0.21(p=0.15)$ at the $3 \mathrm{Y}$ follow-up. VF (measured with the V4e isopter area with the Octopus $900^{\circledR}$, Haag-Streit AG Bern, Switzerland), 
Table 1. All RO parameters

\begin{tabular}{|c|c|c|c|c|}
\hline \multirow{2}{*}{$\begin{array}{l}\text { RO parameter } \\
(\text { mean } \pm S D)\end{array}$} & \multicolumn{3}{|l|}{ Follow-up } & \multirow{2}{*}{$\begin{array}{l}p \text { value over all } \\
\text { follow-up visits } \\
\text { (ANOVA) }\end{array}$} \\
\hline & $\mathrm{BL}$ & $6 \mathrm{M}$ & $3 Y$ & \\
\hline $\mathrm{A}-\mathrm{SO}_{2}, \% \mathrm{SO}_{2}$ & $96.35 \pm 12.76$ & $100.72 \pm 5.53$ & $100.89 \pm 5.87$ & 0.2179 \\
\hline $\mathrm{A}-\mathrm{V} \mathrm{SO}{ }_{2}, \% \mathrm{SO}_{2}$ & $34.15 \pm 8.68$ & $38.93 \pm 9.67$ & $36.23 \pm 7.71$ & 0.2662 \\
\hline $\mathrm{VSO}_{2}, \% \mathrm{SO}_{2}$ & $62.20 \pm 11.55$ & $62.79 \pm 12.06$ & $64.66 \pm 8.24$ & 0.7746 \\
\hline$D-A, \mu m$ & $76.13 \pm 9.01$ & $74.42 \pm 12.37$ & $72.91 \pm 10.98$ & 0.6754 \\
\hline$D-V, \mu m$ & $96.41 \pm 17.37$ & $91.53 \pm 17.10$ & $91.03 \pm 11.54$ & 0.5239 \\
\hline
\end{tabular}

Oxygen saturation values: $\mathrm{A}-\mathrm{SO}_{2}, \mathrm{~V} \mathrm{SO}_{2}$, and $\mathrm{A}-\mathrm{V} \mathrm{SO}_{2}$ and retinal vessel diameters: $\mathrm{D}-\mathrm{A}$ and $\mathrm{D}-\mathrm{V}$ for all follow-up visits. $\mathrm{BL}$, baseline; $6 \mathrm{M}, 6$ months; $3 \mathrm{Y}, 3$ years; $\mathrm{RO}$, retinal oximetry; $\mathrm{SD}$, standard deviation; $\mathrm{A}-\mathrm{SO}_{2}$, saturation in retinal arterioles; $\mathrm{V} \mathrm{SO}_{2}$, saturation in venules.

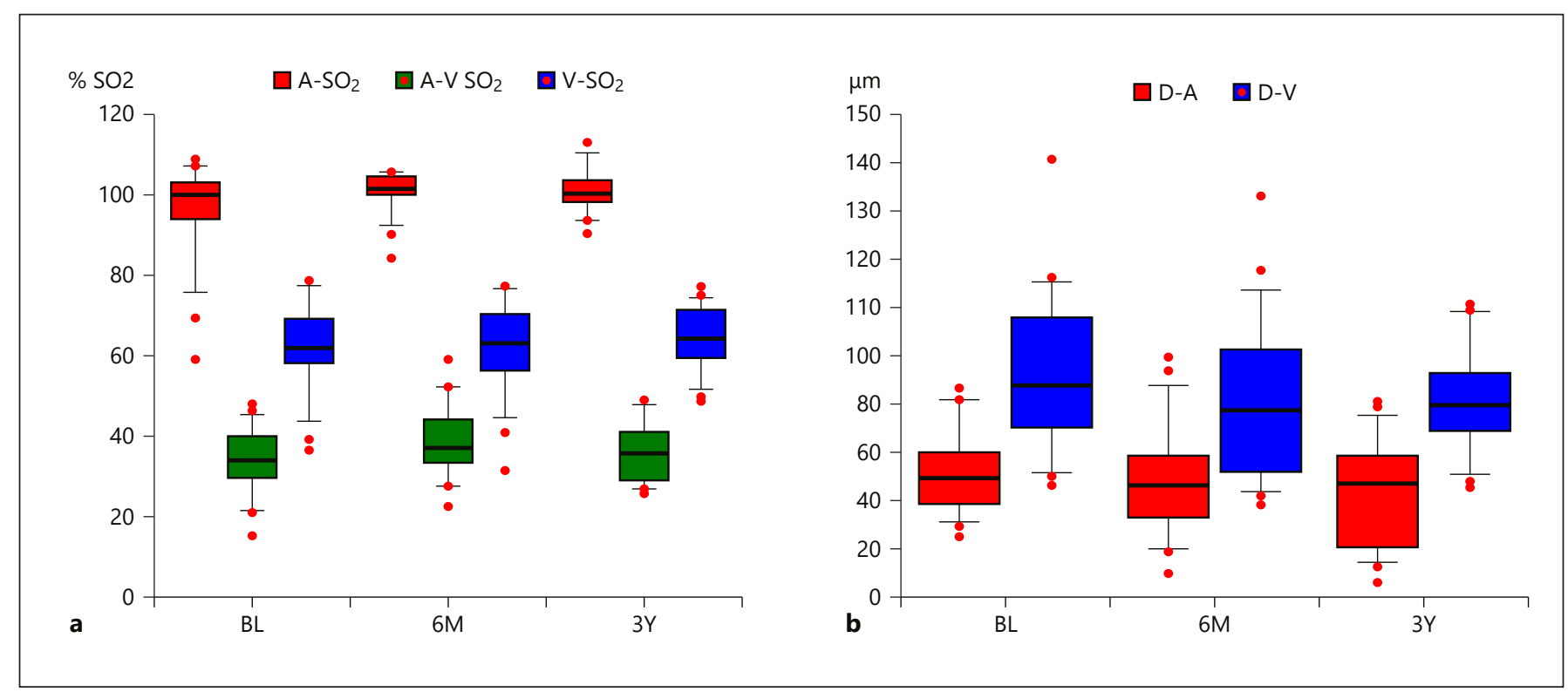

Fig. 2. Box plot analysis presents all RO parameters (oxygen saturation levels in $\mathbf{a}$ and retinal vessel diameters in $\mathbf{b}$ ) throughout the time course of TES. a Oxygen saturation levels of the retinal arterioles (red, $\mathrm{A}-\mathrm{SO}_{2}$ ), venules (blue, $\mathrm{V} \mathrm{SO}_{2}$ ) and their difference (green, $\mathrm{A}-\mathrm{V} \mathrm{SO}_{2}$ ) are indicated on the $y$ axis that represents the oxygen saturation in percent for all follow-up visits shown on the $x$ axis. $\mathbf{b}$ Diameters of the retinal arterioles (red, D-A) and venules (blue, $\mathrm{D}-\mathrm{V}$ ) are indicated on the $y$ axis that represents the

was $4,979.51 \pm 4,489.37 \mathrm{deg}^{2}$ at BL, improved slightly to $5,016.43 \pm 4,664.10 \mathrm{deg}^{2}$ at $6 \mathrm{M}$ and decreased to $4,230.62$ $\pm 3,911.31 \mathrm{deg}^{2}$ at the 3 Y follow-up $(p=0.83)$. None of the RO parameters showed a statistically significant influence by spherical equivalent, age or gender (all $p>0.07$ ). A subset of patients was screened for mutations in retinal disease genes and mutations in the following genes were found: 2 cases with USH2A, 3 cases with EYS, 1 case each with USH3A (CLRN1), RHO, and RP1.

Transcorneal Electrical Stimulation and Retinitis Pigmentosa measurements in micrometers for all follow-up visits shown on the $x$ axis. The upper and lower whiskers of each box plot represent the minimum and maximum value; the upper and lower border of the box itself represents the 25 th and 75 th percentile. The black horizontal bar within the box indicates the median. Data points classified as outliers are marked as red dots. TES, transcorneal electrical stimulation; $\mathrm{RO}$, retinal oximetry; $\mathrm{A}-\mathrm{SO}_{2}$, saturation in retinal arterioles; $\mathrm{V} \mathrm{SO}_{2}$, saturation in venules.

\section{Oximetry Results}

Comparison of Oxygen Saturation Values at BL, 6M, and $3 \mathrm{Y}$ after TES

In general, all oximetry parameters increased slightly throughout the TES timeline without reaching statistical significance: $\mathrm{A}-\mathrm{SO}_{2}$ was $96.35 \pm 12.76 \%$ at $\mathrm{BL}, 100.72 \pm$ $5.53 \%$ at $6 \mathrm{M}(p=0.30$, when compared to BL, Table 1 ; Fig. 2), and $100.89 \pm 5.87 \%$ at the $3 \mathrm{Y}$ follow-up ( $p=0.27$, compared to $\mathrm{BL}$ ). Also, the $\mathrm{V} \mathrm{SO}_{2}$ showed a slight increment 
from $62.20 \pm 11.55 \%$ at BL to $62.79 \pm 12.06 \%$ at $6 \mathrm{M}(p=$ 0.98 , compared to $\mathrm{BL}$ ) and $64.66 \pm 8.24 \%$ at the $3 \mathrm{Y}$ followup ( $p=0.77$, compared to $\mathrm{BL})$. Furthermore, the arteriovenular oxygen difference $\mathrm{A}-\mathrm{V} \mathrm{SO} \mathrm{S}_{2}$ which showed significant changes in the pilot study did not present similar results in the long-term time course of TES: A-V SO 2 initially increased from $34.15 \pm 8.68 \%$ at BL to $38.93 \pm 9.67 \%$ at $6 \mathrm{M}(p=0.2369$, compared to $\mathrm{BL})$. However, at the $3 \mathrm{Y}$ follow-up, the $\mathrm{A}-\mathrm{V} \mathrm{SO}_{2}$ showed no further increment and remained slightly higher than at BL with $36.23 \pm 7.71 \%$ ( $p=0.7553$, compared to $\mathrm{BL}$ ). We found no significant differences in all pairwise comparisons between all follow-up visits $(p>0.05)$.

\section{Retinal Vessel Diameter Results}

Comparison of Retinal Vessel Diameter at BL, 6M, and $3 \mathrm{Y}$ after TES

As for the oxygen saturation, also the retinal vessel diameter results (D-A and D-V) throughout the time course of TES showed only slight changes; however, without reaching statistically significant results (Table 1; Fig. 2). Also, we found no significant difference in all pairwise comparisons between all follow-up visits.

\section{Discussion/Conclusion}

TES is a novel treatment approach for patients suffering from RP and currently the only evidence-based method to slow down disease progression $[1,2,30,31]$. The pathophysiological background is not yet fully understood $[1,2]$. However, studies in animals could confirm TES to induce a release of neurotrophic factors and thus change the microenvironment which improves the survival of the remaining retinal cells, and subsequently slows down the disease progression in RP [2-9]. Furthermore, due to its noninvasive nature and good safety profile with minimal side effects, this therapy option has become more and more popular among RP patients of both early and advanced stages of disease [1-3].

To date, therapy monitoring of TES has been evaluated with ffERG and VF measurements [1,2]. However, both measurements have their limitations: as the ffERG is extinguished very early in the course of RP; it can often no longer be used for monitoring purposes $[1,2,25]$. Furthermore, as VF testing is a very time-consuming method and highly dependent on the cooperation of the patient it often produces very variable results which make a proper comparison of the findings very difficult.
In contrast to ffERG and VF testing, RO is a new, noninvasive, contact-free, short-lasting, and patientfriendly monitoring tool which has achieved a high acceptance in exploring the metabolic alterations of the retina in vascular and degenerative ophthalmic diseases [10-19]. More precisely, RO allows analyzing simultaneously, the retinal vessel oxygen saturation of the main retinal arterioles and venules as well as their corresponding diameters [32-35]. It has proven to be a valuable diagnostic tool especially for RP presenting with significant changes of the retinal oxygen metabolism: Both, the arteriolar and venous retinal oxygen saturation show an increase, while the arteriovenous difference which represents the retinal oxygen consumption, decreases [10-17]. In adult RP patients, these changes are accompanied by a severe vasoconstriction of the retinal arterioles, and venules as part of a neurovascular remodeling [10-17] while in children suffering from $\mathrm{RP}$, these changes seem not to be as pronounced yet [18]. These findings can be explained pathophysiologically with the progression of retinal photoreceptor degeneration and the consecutive apoptosis in RP which reduces the retinal oxygen consumption and results in a hyperoxygenation of the extracellular space [25]. In addition, the blood-retinal barrier function is known to be impaired in RP [36-38] which results in a protein and oxygen invasion from the choriocapillaris and is thought to lead to further increase in extracellular oxygen accumulation [39]. This higher extracellular oxygen level induces further vasoconstriction and consecutively a reduced blood flow in retinal arteries with further alterations in retinal vascular hemodynamics [40]. As a consequence, a secondary neurovascular remodeling, such as proximal intraretinal pigment migration, inner retinal atrophy, neuronal, or glial migration occur as the atrophy advances [41]. These structural changes appear to be less dynamic than retinal vascular oxygen metabolism $[21,25]$. All the above-discussed pathophysiological changes are also reflected in the RO measurements [10-17]. Therefore, by using RO several studies could show that the measurement of the retinal oxygen metabolism can be of diagnostical value [17-19, 21, 25].

Our pilot study including $43 \mathrm{RP}$ eyes showed for the first time that RO might be useful for therapy monitoring in TES and found a significantly increased $\mathrm{A}-\mathrm{V} \mathrm{SO}_{2}$ which represents the retinal oxygen consumption after $6 \mathrm{M}$ of treatment [25]. We assume that with the release of neurotrophic factors, TES improves the survival of photoreceptor cells which consecutively results in increased retinal
56

Ophthalmic Res 2022;65:52-59

DOI: $10.1159 / 000519998$
Meral et al. 
oxygen consumption $[20,25]$. However, it was unclear, whether this effect would also hold true for long-term TES. Therefore, in this study, we compared retinal vessel oxygen saturation parameters in RP patients undergoing TES therapy over a period of up to $3 Y$ to find changes that would be attributed to the therapeutic intervention. In general, the $\mathrm{A}-\mathrm{V} \mathrm{SO}_{2}$ which had shown significant changes in the pilot study did not present similar results in long-term TES. The retinal oxygen consumption seems to increase throughout the TES timeline and remain on higher levels than what was measured at the BL visit; however, without reaching statistical significance. Nevertheless, our study could show that these higher levels of retinal oxygen consumption were also accompanied by relatively stable visual acuity and VF results over the period of 3Y TES treatment: both visual acuity and VF measurements did not show any significant deterioration. These findings further support the hypothesis of improved survival of the remaining retinal cells through TES-induced release of neurotrophic factors [2-9].

Our study has some limitations with a certain genetic and phenotypic heterogeneity of RP patients and a smaller sample size than what we reported in the pilot study. Unfortunately, due to the ongoing COVID-19 pandemic, a lot of patients avoided their follow-up visits in the hospital and could not be included in the present study. Therefore, we cannot exclude the possibility that the oximetry parameters would have reached statistical significance with a higher sample size. Further randomized, double-blinded, and controlled studies are needed to provide a clear evidence-based recommendation to use RO for TES therapy monitoring. In conclusion, our study could show that metabolic monitoring might be of potential diagnostic value in the context of TES. However, further studies are needed to verify its use in daily clinical practice.

\section{Acknowledgment}

We thank Mr Corrado della Volpe, MSc for editing the manuscript.

\section{Statement of Ethics}

All procedures performed in studies involving human participants were in accordance with the ethical standards of the institutional and/or national research committee and with the $1964 \mathrm{Hel}-$ sinki Declaration and its later amendments or comparable ethical standards. Study approval statement: This study protocol was reviewed and approved by the local IRB EKNZ in Basel, BASEC
2020-00122. Consent to participate statement: written informed consent was obtained from all individual participants included in this study.

\section{Conflict of Interest Statement}

Dr. Scholl is member of the Scientific Advisory Board of Apellis Switzerland GmbH, ARCTOS medical AG; Astellas Pharma Global Development, Inc./Astellas Institute for Regenerative Medicine; Biogen MA Inc.; Boehringer Ingelheim Pharma GmbH \& Co; Gyroscope Therapeutics Ltd.; Janssen Research \& Development, LLC (Johnson \& Johnson); Novartis Pharma AG (CORE); Okuvision GmbH; Pharma Research \& Early Development (pRED) of F. Hoffmann-La Roche Ltd; ReVision Therapeutics, Inc.; and Stargazer Pharmaceuticals, Inc. Dr. Scholl is paid consultant of Gerson Lehrman Group; Guidepoint Global, LLC; Tenpoint Therapeutics Limited; and Third Rock Ventures, LLC. Dr. Scholl is member of the Data Monitoring and Safety Board/Committee of Belite Bio and ReNeuron Group Plc/Ora Inc. and member of the Steering Committee of Novo Nordisk (FOCUS trial). Dr. Scholl is co-director of the Institute of Molecular and Clinical Ophthal Basel (IOB) which is constituted as a nonprofit foundation and receives funding from the University of Basel, the University Hospital Basel, Novartis, and the government of Basel-Stadt. These arrangements have been reviewed and approved by the University of Basel (Universitätsspital Basel, USB) in accordance with its conflict of interest policies. Dr. Hendrik Scholl is principal investigator of grants at the USB sponsored by the following entity: IVERIC bio (Ophthotech Corporation); Kinarus AG; and Novartis Pharma AG. Grants at USB are negotiated and administered by the institution (USB) which receives them on its proper accounts. Prof. Scholl is the Editor-in-Chief of the journal. Individual investigators who participate in the sponsored project(s) are not directly compensated by the sponsor but may receive salary or other support from the institution to support their effort on the project(s).

\section{Funding Sources}

Hendrik P. N. Scholl was supported by the Swiss National Science Foundation, National Center of Competence in Research Molecular Systems Engineering "Molecular Systems Engineering" and project funding in biology and medicine ("Developing novel outcomes for clinical trials in Stargardt disease using structure/function relationship and deep learning" \#310030_201165), the Wellcome Trust (PINNACLE study), the Translational Research Acceleration Program Award by the Foundation Fighting Blindness ("Cone-based optogenetics for vision restoration" \#TA-NMT-0621-0805-TRAP), and the Foundation Fighting Blindness Clinical Research Institute (ProgStar study). Maria della Volpe Waizel was supported by the SAMW (Schweizerische Akademie der Medizinischen Wissenschaften), the Bangerter Foundation and the SNF (Swiss National Science Foundation) with ad personam grants. The sponsor had no role in the design or conduct of this research. All other authors certify that they have no affiliations with or involvement in any organization or entity with any financial interest (such as honoraria; educational grants; participation in speakers' bureaus; membership, employment, consultancies, stock ownership, or other equity interest; and expert testimony or patent- 
licensing arrangements), or nonfinancial interest (such as personal or professional relationships, affiliations, knowledge, or beliefs) in the subject matter or materials discussed in this manuscript.

\section{Author Contributions}

Nesrin Meral and Olga Zabek contributed to conceptualization and drafting of the article. Maria della Volpe Waizel contributed to data preparation, interpretation, and revision of the draft article. All co-authors contributed to writing, provided intellectual input, and approved the final version of the article.

\section{Data Availability Statement}

The data that support the findings of this study are not publicly available due to their containing information that could compromise the privacy of research participants but are available from the corresponding author.

\section{References}

1 Schatz A, Röck T, Naycheva L, Willmann G, Wilhelm B, Peters T, et al. Transcorneal electrical stimulation for patients with retinitis pigmentosa: a prospective, randomized, sham-controlled exploratory study. Invest Ophthalmol Vis Sci. 2011 Jun;52(7):4485-96.

2 Schatz A, Pach J, Gosheva M, Naycheva L, Willmann G, Wilhelm B, et al. Transcorneal electrical stimulation for patients with retinitis pigmentosa: a prospective, randomized, sham-controlled follow-up study over 1 year. Invest Ophthalmol Vis Sci. 2017 Jan;58(1): 257-69.

3 Morimoto T, Miyoshi T, Matsuda S, Tano Y, Fujikado T, Fukuda Y. Transcorneal electrical stimulation rescues axotomized retinal ganglion cells by activating endogenous retinal IGF-1 system. Invest Ophthalmol Vis Sci. 2005 Jun;46(6):2147-55.

4 Geremia NM, Gordon T, Brushart TM, AlMajed AA, Verge VM. Electrical stimulation promotes sensory neuron regeneration and growth-associated gene expression. Exp Neurol. 2007 Jun;205(2):347-59.

5 Sato T, Fujikado T, Lee TS, Tano Y. Direct effect of electrical stimulation on induction of brain-derived neurotrophic factor from cultured retinal Müller cells. Invest Ophthalmol Vis Sci. 2008 Jun;49(10):4641-6.

6 Schmid H, Herrmann T, Kohler K, Stett A. Neuroprotective effect of transretinal electrical stimulation on neurons in the inner nuclear layer of the degenerated retina. Brain Res Bull. 2009 Apr;79(1):15-25.

7 Ciavatta VT, Kim M, Wong P, Nickerson JM, Shuler RK Jr, McLean GY, et al. Retinal expression of Fgf2 in RCS rats with subretinal microphotodiode array. Invest Ophthalmol Vis Sci. 2009 Oct;50(10):4523-30.

8 Ni YQ, Gan DK, Xu HD, Xu GZ, Da CD. Neuroprotective effect of transcorneal electrical stimulation on light-induced photoreceptor degeneration. Exp Neurol. 2009 Oct;219(2): 439-52.

9 Fu L, Lo AC, Lai JS, Shih KC. The role of electrical stimulation therapy in ophthalmic diseases. Graefes Arch Clin Exp Ophthalmol. 2015;253(2):171-6.
10 Todorova MG, Türksever C, Schorderet DF, Valmaggia C. Retinal vessel oxygen saturation in patients suffering from inherited diseases of the retina. Klin Monbl Augenheilkd. 2014 Apr;231(4):447-52.

11 Türksever C, Valmaggia C, Orgül S, Schorderet DF, Flammer J, Todorova MG. Retinal vessel oxygen saturation and its correlation with structural changes in retinitis pigmentosa. Acta Ophthalmol. 2014 Apr;92(5):454-60.

12 Lopez Torres LT, Türksever C, Schötzau A, Orgül S, Todorova MG. Peripapillary retinal vessel diameter correlates with mfERG alterations in retinitis pigmentosa. Acta Ophthalmol. 2015 March;93(7):e527-33.

13 Todorova MG, Türksever C, Schötzau A, Schorderet DF, Valmaggia C. Metabolic and functional changes in retinitis pigmentosa: comparing retinal vessel oximetry to full-field electroretinography, electrooculogram and multifocal electroretinography. Acta Ophthalmol. 2015 Oct;94(3):e231-41.

14 Konieczka K, Bojinova RI, Valmaggia C, Schorderet DF, Todorova MG. Preserved functional and structural integrity of the papillomacular area correlates with better visual acuity in retinitis pigmentosa. Eye. 2016 Oct; 30(10):1310-23.

15 Bojinova RI, Türksever C, Schötzau A, Valmaggia C, Schorderet DF, Todorova MG. Reduced metabolic function and structural alterations in inherited retinal dystrophies: investigating the effect of peripapillary vessel oxygen saturation and vascular diameter on the retinal nerve fibre layer thickness. Acta Ophthalmol. 2017 Sep;95(3):252-61.

16 Bojinova RI, Schorderet DF, Valmaggia C, Türksever C, Schoetzau A, Todorova MG. Higher retinal vessel oxygen saturation: investigating its relationship with macular oedema in retinitis pigmentosa patients. Eye. 2018 Jul;32(7):1209-19.

17 Waizel M, Türksever C, Todorova MG. The effect of autoimmune retinopathy on retinal vessel oxygen saturation. Eye. 2018 Sep;32(9): 1455-62.
18 Della Volpe Waizel M, Scholl HPN, Valmaggia C, Todorova MG. Retinal vessel oximetry in children with inherited retinal diseases. Acta Ophthalmol. 2021 Feb;99(1):52-60.

19 Todorova MG, Scholl HPN, Della Volpe Waizel M. The impact of macular edema on microvascular and metabolic alterations in retinitis pigmentosa. Graefes Arch Clin Exp Ophthalmol. 2020 Sep;259(3):643-52.

20 Zabek O, Camenzind Zuche H, Müller U, Scholl HPN, Rickmann A, Della Volpe Waizel M. Optical coherence tomography angiography findings in patients undergoing transcorneal electrical stimulation for treating retinitis pigmentosa. Graefes Arch Clin Exp Ophthalmol. 2020 Oct;259(5): 1167-77.

21 Della Volpe Waizel M, Scholl HPN, Todorova MG. Microvascular and metabolic alterations in retinitis pigmentosa and Stargardt disease. Acta Ophthalmol. 2021 Dec;99(8):e1396e1404.

22 Stefánsson E, Wolbarsht ML, Landers MB 3rd. In vivo $\mathrm{O} 2$ consumption in rhesus monkeys in light and dark. Exp Eye Res. 1983 Sep; 37(3):251-6.

23 Jakobsen DB, Torp TL, Stefansson E, Peto T, Grauslund J. Retinal metabolic and structural alterations in response to aflibercept treatment in neovascular age-related macular degeneration. Acta Ophthalmol. 2019 Aug; 97(5):525-31.

24 Bek T, Jørgensen CM. The systemic blood pressure and oxygen saturation in retinal arterioles predict the effect of intravitreal antivegf treatment on diabetic maculopathy. Invest Ophthalmol Vis Sci. 2016 Oct;57(13): 5429-34.

25 Della Volpe-Waizel M, Camenzind Zuche H, Müller U, Rickmann A, Scholl HPN, Todorova MG. Metabolic monitoring of transcorneal electrical stimulation in retinitis pigmentosa. Graefes Arch Clin Exp Ophthalmol. 2020 Jan; 258(1):79-87.

26 McCulloch DL, Marmor MF, Brigell MG, Hamilton R, Holder GE, Tzekov R, et al. ISCEV Standard for full-field clinical electroretinography (2015 update). Doc Ophthalmol. 2015 Feb;130(1):1-12. 
27 Yu DY, Cringle SJ. Oxygen distribution and consumption within the retina in vascularised and avascular retinas and in animal models of retinal disease. Prog Retin Eye Res. 2001 Mar; 20(2):175-208.

28 Wangsa-Wirawan ND, Linsenmeier RA. Retinal oxygen: fundamental and clinical aspects. Arch Ophthalmol. 2003 Apr;121(4): 547-57.

29 Yu DY, Cringle SJ. Retinal degeneration and local oxygen metabolism. Exp Eye Res. 2005 Jun;80(6):745-51.

30 Morimoto T, Kanda H, Kondo M, Terasaki H, Nishida K, Fujikado T. Transcorneal electrical stimulation promotes survival of photoreceptors and improves retinal function in rhodopsin P347L transgenic rabbits. Invest Ophthalmol Vis Sci. 2012 Jun;53: 4254-61.

31 Morimoto T, Fujikado T, Choi JS, Kanda H, Miyoshi T, Fukuda Y, et al. Transcorneal electrical stimulation promotes the survival of photoreceptors and preserves retinal function in royal college of surgeons rats. Invest Ophthalmol Vis Sci. 2007 Oct;48(10):4725-32.
32 Schweitzer D, Thamm E, Hammer M, Kraft J. A new method for the measurement of oxygen saturation at the human ocular fundus. Int Ophthalmol. 2001;23(4-6):347-53.

33 Hammer M, Thamm E, Schweitzer D. A simple algorithm for in vivo ocular fundus oximetry compensating for non-haemoglobin absorption and scattering. Phys Med Biol. 2002 Sep;47(17):N233-8.

34 Hardarson SH, Harris A, Karlsson RA, Halldorsson GH, Kagemann L, Rechtman $\mathrm{E}$, et al. Automatic retinal oximetry. Invest Ophthalmol Vis Sci. 2006 Sep;47(11): 5011-6.

35 Yu DY, Cringle SJ. Oxygen distribution and consumption within the retina in vascularised and avascular retinas and in animal models of retinal disease. Prog Retin Eye Res. 2001 Mar; 20(2):175-208.

36 Marc RE, Jones BW. Retinal remodeling in inherited photoreceptor degenerations. Mol Neurobiol. 2003 Oct;28(2):139-47.
37 Marc RE, Jones BW, Watt CB, Strettoi E. Neural remodeling in retinal degeneration. Prog Retin Eye Res. 2003 Sep;22(5):60755.

38 Zhang Y, Harrison JM, Nateras OS, Chalfin S, Duong TQ. Decreased retinal-choroidal blood flow in retinitis pigmentosa as measured by MRI. Doc Ophthalmol. 2013 Feb;126(3):18797.

39 Milam AH, Li ZY, Fariss RN. Histopathology of the human retina in retinitis pigmentosa. Prog Retin Eye Res. 1998 Apr;17(2):175-205.

40 Beutelspacher SC, Serbebic N, Barash H, Burgansky-Eliash Z, Grinvald A, Krastel H, et al. Retinal blood flow velocity measured by retinal function imaging in retinitis pigmentosa. Graefes Arch Clin Exp Ophthalmol. 2001 Dec; 249(12):1855-8

41 Jones BW, Pfeiffer RL, Ferrell WD, Watt CB, Marmor M, Marc RE. Retinal remodeling in human retinitis pigmentosa. Exp Eye Res. 2016 Sept;150:149-65. 